Supporting Information

\title{
A Highly Stretchable Polyacrylonitrile Elastomer with Nanoreservoirs of Lubricant Using Cyano- Silver Complexes
}

Songlin Zhang*, Ayou Hao, Zhe Liu, Jin Gyu Park*, and Richard Liang

High-Performance Materials Institute, Department of Industrial and Manufacturing Engineering, FAMU-FSU College of Engineering, Florida State University, 2005 Levy Ave., Tallahassee, FL 32310, USA

*Correspondence to: sz15c@my.fsu.edu (Songlin Zhang), jgpark@fsu.edu (Jin Gyu Park) 
This PDF file includes:

\author{
Materials \\ Methods \\ Supplementary Text \\ Tables S1 and S2 \\ Figures S1 to S15 \\ Captions for Video S1 to S4 \\ References
}

Other supplementary material for this manuscript includes the following: Video S1 to S4 


\section{Materials.}

The polyacrylonitrile (PAN, average $\mathrm{M}_{\mathrm{w}}$ 150,000 (typical) Vinyl cyanide), N, NDimethylformamide (DMF), and silver nitrate $\left(\mathrm{AgNO}_{3}, \mathrm{ACS}\right.$ reagent, $\left.\geq 99.0 \%\right)$ were purchased from Sigma-Aldrich.

\section{Methods.}

Fabrication of Ag+/PAN elastomers.

In this study, all chemicals were used as received without any purifications. Based on the different mass ratios, $R(\mathrm{x})$ of $\mathrm{AgNO}_{3}$ versus PAN (x, the ratio of $\mathrm{AgNO}_{3}: \mathrm{PAN}$ in weight, see Table S2 for more details), samples of group 1 to group 6 were fabricated, corresponding to the ratio of $R(0)$ to $R(1.1)$. First, for instance, $8 \mathrm{ml}$ DMF solvent was poured into a vial. Then 160 mg PAN powder was carefully added to the vial (note: the percentage between PAN (m, in weight of milligram) and DMF (v, in volume of milliliter) was fixed to $2 \%(\mathrm{w} / \mathrm{v}))$. Then the mixture was stirred for 2 hours (Hotplate/Stirrer, VWR). A designed amount of $\mathrm{AgNO}_{3}$ was added to the above mixture of PAN/DMF and stirred for another 1 hour. Teflon mold was used to assist the formation of $\mathrm{Ag}^{+} / \mathrm{PAN}$ elastomers using vacuum oven (Isotemp®, Model 230A, Fisher Scientific) at $50{ }^{\circ} \mathrm{C}$ for 36 hours. The control sample of pure PAN film with $R(0)$ was prepared as same as the $\mathrm{Ag}^{+} / \mathrm{PAN}$ elastomers just without adding $\mathrm{AgNO}_{3}$. The effect of drying temperature on the mechanical response was studied using samples fabricated at drying temperature of $70{ }^{\circ} \mathrm{C}$.

\section{Uniaxial mechanical tests.}

All specimens were cut and prepared using dimensions of $\sim 10 \mathrm{~mm}$ in gauge length, $\sim 4 \mathrm{~mm}$ in width with sandpaper tabs at both ends (total specimen length is greater than $20 \mathrm{~mm}$ ). The uniaxial tensile tests were performed using Autograph AG-X (Shimadzu Corp.) with tensile mode at speed of $5 \mathrm{~mm} \cdot \mathrm{min}^{-1}$. For cyclic tests, all samples were also conducted at the speed of 
$5 \mathrm{~mm} \cdot \mathrm{min}^{-1}$. Test program was set with following procedures. First the sample was subject to stretch directly from $0 \%$ to the desired percentage (e.g.: 200\%), then immediately released back to the original position at $5 \mathrm{~mm} \cdot \mathrm{min}^{-1}$. Subsequently, the interval time started to count (e.g.: 10 min). The second cycle test started right after the end of 10 min rest. Then repeating the same procedure as what in the first cycle was applied. All cyclic tests with different stretching percentage $(20 \%, 50 \%, 100 \%, 200 \%, 300 \%, 400 \%, 500 \%)$ in Figure $3 \mathrm{~A}$ were performed on the same sample with interval time of $10 \mathrm{~min}$. To study the effect of interval time on the recovery of stretched samples, cyclic tests at $200 \%$ was also conducted with various interval time from $0,5,10$, to $30 \mathrm{~min}$ (all tests were conducted on the same specimen). Stress relaxation was performed by holding the specimen at $100 \%$ stretching percentage for 60 min while recording the force change.

\section{Dynamic Mechanical Analysis (DMA)}

To further study the mechanical response with regard to polymer chain movement, viscoelastic behavior of the new $\mathrm{Ag}^{+} / \mathrm{PAN}$ elastomer was assessed using DMA (TA model Q800) with multiple frequency-strain mode. Amplitude was set at $50 \mu \mathrm{m}$ while varying the frequency from $1 \mathrm{~Hz}$ to $200 \mathrm{~Hz}$. Sample size is around $5 \mathrm{~mm}$ in width and $100 \mu \mathrm{m}$ in thickness with a gauge length of $10 \mathrm{~mm}$.

\section{Fourier-transform infrared (FT-IR) spectroscopy.}

The as-prepared $\mathrm{Ag}^{+} / \mathrm{PAN}$ elastomers were used directly for FT-IR spectra characterization using Golden Gate ${ }^{\mathrm{TM}}$ ATR mode with a diamond window. Data were collected with total 32 scans for each specimen between $4000-400 \mathrm{~cm}^{-1}$ using a Thermo Nicolet NEXUS 470 FR-IR spectrometer, which were then analyzed using the OMNIC software (Thermo Fisher Scientific, Inc.).

Differential scanning calorimetry (DSC). 
The thermal properties including glass transition temperature $\left(\mathrm{T}_{\mathrm{g}}\right)$ of all samples were characterized using DSC (TA Instruments Q100) in the range of $-90{ }^{\circ} \mathrm{C}$ to $50{ }^{\circ} \mathrm{C}$. The testing program was designed to first cool down to $-90{ }^{\circ} \mathrm{C}$ with isothermal setting for $5 \mathrm{~min}$. Then 2 cycles of heating-cooling were performed with a ramp rate at $5^{\circ} \mathrm{C} \cdot \mathrm{min}^{-1}$. The $T_{\mathrm{g}}$ of PAN powder was determined by running DSC in the range of $50{ }^{\circ} \mathrm{C}$ to $350{ }^{\circ} \mathrm{C}$.

$\underline{\text { Scanning electron microscopy (SEM) and energy dispersive X-ray spectroscopy (EDX). }}$

Electron images were taken using JSM-7401F (JEOL) with a field emission gun. Samples were sputter-coated with gold/palladium alloy layer $(\sim 5 \mathrm{~nm}$ in thickness) before any further characterizations. Low acceleration voltage of $3 \mathrm{kV}$ was used for the morphology characterization to avoid possible beam damages. EDX data were obtained using FEI Nova400 equipped with Oxford Ultim ${ }^{\circledR}$ Max silicon drift detector (SDD). Both line scan and area mapping of specimen's cross-section were performed at $10 \mathrm{kV}$, which is two times higher than the L-edge absorption energy of silver.

\section{$\underline{\text { High-resolution Transmission electron microscopy (HRTEM) and Scanning TEM (STEM) }}$}

\section{EDX.}

Since the elastomers are soft and flexible, following procedures were carried out to assist the sample preparation for TEM characterization. First the $\mathrm{Ag}^{+} / \mathrm{PAN}$ elastomer sample with $R(1.0)$ was embedded within Epo-Fix resin 1232-R (mixed with Epo-Fix hardener 1232-H, Electron Microscopy Science, Inc.).Then curing of 4 hours at $70{ }^{\circ} \mathrm{C}$ was applied to harden the resin, which assisted the following sample cutting process. The Ultracut UC6 (Leica Microsystems, Germany) was used to cut the resin embedded sample into ultra-thin slices at room temperature with a feed step at $25 \mathrm{~nm}$. These slices were then collected on a copper grid with a support of lacey-carbon (Electron Microscopy Science, Inc.). TEM characterization was performed at $80 \mathrm{kV}$ using the JEM-ARM200cF ( $C_{\mathrm{s}}$ Corrected, JEOL, Ltd., Japan). The Scanning TEM was also done at $80 \mathrm{kV}$. Oxford Ultim ${ }^{\circledR}$ Max silicon drift detector (SDD) is used for EDX mapping. 
To achieve an efficient data collection, a spot size of 4C (corresponding to a current of $324 \mathrm{pA}$ ) was applied to excite the X-ray. Both STEM bright field (BF) and annual dark field (ADF) images were recorded. STEM EDX mapping data was related to the black square area in ADF image (Figure S12B). And its corresponding spectrum was also collected.

\section{Thermogravimetric analysis (TGA).}

The weight percent of DMF within $\mathrm{Ag}^{+} / \mathrm{PAN}$ elastomer samples after drying at $50{ }^{\circ} \mathrm{C}$ was evaluated using TGA (TA Instruments Q50) in the range of $50{ }^{\circ} \mathrm{C}$ to $600{ }^{\circ} \mathrm{C}$ with a ramp rate of $10{ }^{\circ} \mathrm{C} \cdot \mathrm{min}^{-1}$. Due to the different decomposition temperatures of compositions of $\mathrm{Ag}^{+} / \mathrm{PAN}$ elastomers, the DMF weight percent was calculated based on the weight change in the temperature range between the onset and endpoint of the first derivative weight change peak (Figure S4, a peak centered at $\sim 175{ }^{\circ} \mathrm{C}$, which is close to the boiling point of DMF, $153{ }^{\circ} \mathrm{C}$ ). In this study, evaporation instead of decomposition happened to DMF during temperature ramping.

\section{$\underline{\text { Sensibility test of Ag+/PAN elastomer itself as sensors. }}$}

The electrical response of $\mathrm{Ag}^{+} / \mathrm{PAN}$ elastomer under tensile stretching-releasing cycles was recorded by monitoring the voltage change of a sample. Without adding any additional conductive fillers such nanocarbon materials, silver nano particles or liquid metal, ${ }^{1-5}$ this elastomer can be directly used as strain sensor. For a quick strain sensor demonstration, the test speed was set as $20 \mathrm{~mm} \cdot \mathrm{min}^{-1}$ and the amplitude was $50 \%$ strain. After each cycle, there was 5 seconds as interval rest time. For the concept-of-proof demonstration of an electronic "skin", a film sample was connected to four copper electrodes. Two diagonal electrodes were connected to current source and the other two connected to voltmeter. When test started, the sample was subject to air blow from mouth (with random depth and speed) and showed a clear and fast corresponding response qualitatively. 
$\underline{\text { Small- and wide-angle X-ray scattering (SAXS and WAXS) with in situ stretching. }}$

SAXS and WAXS measurements were obtained on a Bruker NanoSTAR system with an Incoatec I $\mu \mathrm{S}$ microfocus $\mathrm{X}$-ray source operating at $45 \mathrm{kV}$ and $650 \mu \mathrm{A}$. The beam was collimated with cross-coupled Göbel mirrors and three pin-hole system, providing a $\mathrm{Cu} K_{\alpha}$ radiation beam $(\lambda=0.154 \mathrm{~nm})$ with a beam size about $0.15 \mathrm{~mm}$ in full width half maximum (FWHM) at the sample position. The WAXS intensity was captured by a Fuji Photo Film image plate and read with a Fuji FLA-7000 scanner. The SAXS intensity was recorded by 2D HiSTAR detector. For the SAXS characterization of specimen at different stretching percentage, an in-situ mechanical stretching stage (Anton-Paar TS600) was used to deform the sample to a specified strain. The SAXS data at $0 \%$ was collected first, then the sample was deformed to $50 \%$ for the next SAXS data collection. Similarly, SAXS data at 100\%, 200\%, 300\%, 400\%, 500\%, 600\% were obtained respectively.

\section{Supplementary Text}

The formation of two-phase structure with nano-reservoirs using cyano-silver complexes

The drying condition (temperature) was found to be critical for the successful fabrication of elastomers. When leaving $\mathrm{Ag}^{+} / \mathrm{PAN}$ mixture at room temperature for one month, the gelation happened (Figure S1, and Video S1) with a typical interconnected microstructure for gel materials by cyano-silver complexes ${ }^{6}$. For the elastomer prepared with $50{ }^{\circ} \mathrm{C}$ drying condition, the DMF evaporation rate was accelerated. As a consequence, the accumulated vapor pressure of DMF increased. The network of PAN chains with coordination bond tended to form an interconnected structure without DMF due to its high entropy. However, once the network formed on the outer surface during drying, the residual DMF could be trapped within the as-prepared elastomers (cannot escape at this temperature). Therefore, two phases (at nanoscale) including DMF rich area (the cell, or nano-reservoirs) and the cell walls of 
coordination-bonded PAN chains rich area formed at $50{ }^{\circ} \mathrm{C}$ (as illustrated in Figure S13A). Additionally, theses trapped DMF can still serve the function of solvent as lubricant which ensure the good fluidity of polymer chains within the elastomer when being deformed (Figure 4D). Higher drying temperature (e.g.: $70^{\circ} \mathrm{C}$ ) may lead to an even higher vapor pressure of DMF. Therefore, less DMF was trapped inside, resulted in a smaller stretchability (Figure S5).

Comparing to the case of sample drying at $50{ }^{\circ} \mathrm{C}$, DMF could completely evaporate out from the $\mathrm{Ag}^{+} / \mathrm{PAN}$ film when drying at $90^{\circ} \mathrm{C}$ for 36 hours. Due to the higher vapor pressure $\left(\right.$ at $90{ }^{\circ} \mathrm{C}$ ), a faster evaporation rate was expected. Consequently, the merging effect of neighboring nano-reservoirs (the nanoscale cells expected for elastomers dried at $50{ }^{\circ} \mathrm{C}$ ) occurred, resulting in an observable cellular-like structure with large cell size when DMF was completely removed (as illustrated in Figure S13 A, and images from C1 to C3). This effect was further manifested by drying the elastomer at $150{ }^{\circ} \mathrm{C}$ (Figure S13 A and images from D2 to D3).

In Figure S13, the cellular-like structure with cells was clearly observed after high temperature drying $\left(90{ }^{\circ} \mathrm{C}\right.$ and $150{ }^{\circ} \mathrm{C}$ in this study). The difference of cell size after drying at relatively low $\left(90^{\circ} \mathrm{C}\right)$ and relatively high $\left(150^{\circ} \mathrm{C}\right)$ temperature can possibly attributed to the different evaporation rate of DMF solvent at different heating conditions. When drying at 90 ${ }^{\circ} \mathrm{C}$, the DMF molecules within the nano-reservoirs was pressurized out, which resulted in the breakage of cell walls. The broken cell walls gradually merged into the neighboring cells and formed a big cell. This explained why the cellular-like structure was clearly seen for the film dried at $90{ }^{\circ} \mathrm{C}$; however, no obvious pores or cells were found for the film dried at $50{ }^{\circ} \mathrm{C}$ (cell size was limited to nanometers). Furthermore, when heating at $150{ }^{\circ} \mathrm{C}$, the kinetic energy of DMF molecules within the nano-reservoirs was extremely high, a lot of cells were destroyed 
to allow the evaporation of DMF 'vapor', resulting in the formation of even bigger cells as shown in Figure S13 D2 and D3.

With increasing the ratio, $R(\mathrm{x})$, the density of coordination bond (cyano-silver complexes) increased, too. Therefore, more nano-reservoirs could be formed inside the elastomers with larger $R(\mathrm{x})$. As a result, more DMF was trapped within nano-reservoirs, as verified by the TGA data (explained in Figure S4 and Table S3). The stretchability of elastomers (or fluidity of polymer chains) could be enhanced due to the disperse capability of DMF as 'lubricant'.

The 2D SAXS scattering pattern and polymer chain alignment of elastomers under stretching

The high stretchability of the $\mathrm{Ag}^{+} / \mathrm{PAN}$ elastomers was further investigated by monitoring the conformation of PAN polymer chains when being stretched. The 2D scattering pattern of SAXS was selected as a measurement to detect the microstructure evolution at different strain. In-situ mechanical stretching was applied because a continuous data collection can be achieved with a single sample for all designed strain (in this study including $0 \%, 50 \%, 100 \%, 200 \%, 300 \%, 400 \%, 500 \%, 600 \%)$. As the Figure 4A shown, isotropic microstructure was observed for $0 \%, 50 \%$, and $100 \%$ strain, based on the 2D scattering pattern. This could be clearly understood as illustrated in Figure 4D. The nano-reservoirs within elastomers may be squeezed first to compensate the structural change when being subject to external stretching $(<200 \%)$. The random interconnected polymer chains obviously correlate with the isotropic 2D scattering pattern. When further stretching the elastomer (> $200 \%$ ), the polymer chain extension (or alignment) occurred. Therefore, the alignment could be detected as reflected in the2D scattering pattern. For instance, the anisotropic feature of $2 \mathrm{D}$ scattering pattern appeared for the elastomer when being stretched to $200 \%$ strain (Figure 4D). Gradually, prominent anisotropic structure of polymer chains was verified when the 
elastomer was under high external stretching. Quantitatively, the alignment degree was calculated using Herman's orientation equation ${ }^{7}$ :

$$
\begin{gathered}
f=\frac{3\left\langle\cos ^{2} \phi\right\rangle-1}{2} \\
\cos ^{2} \phi=\frac{\sum_{\phi=0^{\circ}}^{\phi=90^{\circ}} I(\phi) \sin \phi \cos ^{2} \phi}{\sum_{\phi=90^{\circ}}^{\phi=9} I(\phi) \sin \phi}
\end{gathered}
$$

where $f$ is the Herman's orientation factor ( 1 implies the perfect alignment and 0 is total randomness), and $\phi$ is the angle between polymer chains and the uniaxial stretching direction or how far from alignment the polymer chains were from $100 \%$. 
Table S1. The swelling ratio and gel fraction of elastomers with various $R(\mathrm{x})$.

\begin{tabular}{cccc}
\hline Sample name & $\begin{array}{c}\text { Swelling Ratio* } \\
(\%)\end{array}$ & $\begin{array}{c}\text { Gel Fraction } \\
(\%)\end{array}$ & $\begin{array}{c}\text { Sol Fraction } \\
\%\end{array}$ \\
\hline$R(0) \#$ & - & - & - \\
$R(0.5)$ & 19.4 & 79.9 & 20.1 \\
$R(0.7)$ & 21.7 & 87.4 & 12.6 \\
$R(0.9)$ & 23.5 & 92.2 & 7.8 \\
$R(1.0)$ & 25.1 & 94.9 & 5.1 \\
$R(1.1)$ & 29.2 & 95.7 & 4.3 \\
\hline
\end{tabular}

*Note: The swelling ratio was calculated by the weight difference of elastomer in the swollen state, $\mathrm{m}_{1}$ (elastomer dried at $50{ }^{\circ} \mathrm{C}$ for 36 hours) and the initial weight of $\mathrm{AgNO}_{3}$ and $\mathrm{PAN}$, $\mathrm{m}_{0}$, divided by the initial weight $\mathrm{m} 0$, namely $\left(\mathrm{m}_{1}-\mathrm{m}_{0}\right) / \mathrm{m}_{0}$. The gel fraction was simply calculated by the weight ratio of the dried elastomer (after dried at $150{ }^{\circ} \mathrm{C}$ for 2 hours) to its initial weight of $\mathrm{AgNO}_{3}$ and PAN. Other method such as Soxhlet method can also be used to obtain a vigorous value for gel fraction; however, it also has reaction time dependent issues. ${ }^{8}$, ${ }^{9}$ Although a more accurate value of gel fraction needs further study, the gel fraction results show the tendency of coordination bond under the same experimental procedures. The sol fraction was calculated by 1 minus the percentage of the gel fraction.

\#Note: since PAN film with $R(0)$ is not an elastomer and there is no gelation process at room temperature during solution preparation (figure S1 and video S1), the corresponding swelling ratio, gel/sol fraction were not calculated in the above table.

The swelling ratio increased as the ratio $R(\mathrm{x})$ became larger, which is reasonable if the nanoreservoir structure is taken into account. Since larger $R(\mathrm{x})$ corresponds to a higher density of cyano-silver coordination bonds, more nano-reservoirs can be formed (figure S12), indicating a better capability of trapping (or swelling) DMF. 
Table S2. The composition of $\mathrm{Ag}^{+} / \mathrm{PAN}$ elastomers. The mass ratio, $R(\mathrm{x})$ of silver nitrate $\left(\mathrm{AgNO}_{3}\right)$ versus polyacrylonitrile $(\mathrm{PAN})$, and the calculated molar ratio between silver ion $\left(\mathrm{Ag}^{+}\right.$, from the ionization of $\left.\mathrm{AgNO}_{3}\right)$ and nitrile groups $(-\mathrm{C} \equiv \mathrm{N}$ from the backbone of PAN chains).

\begin{tabular}{l|ccc|cccc}
\hline & \multicolumn{2}{|c}{ Group 1 } & \multicolumn{2}{c}{ Group 2 } & \multicolumn{2}{c}{ Group 3 } \\
\cline { 2 - 8 } & $\mathrm{AgNO}_{3}$ & $\mathrm{PAN}$ & $\mathrm{AgNO}_{3}$ & $\mathrm{PAN}$ & $\mathrm{AgNO}_{3}$ & PAN \\
\hline Mass $(\mathrm{mg})$ & 0 & 160 & 80 & 160 & 112 & 160 \\
Mass ratio $(R(\mathrm{x}))$ & \multicolumn{2}{|c|}{0} & \multicolumn{2}{c}{0.5} & \multicolumn{2}{c}{0.7} \\
\hline & $\mathrm{Ag}+$ & $-\mathrm{C} \equiv \mathrm{N}$ & \multicolumn{2}{c|}{$\mathrm{Ag}^{+}$} & $-\mathrm{C} \equiv \mathrm{N}$ & $\mathrm{Ag}^{+}$ & $-\mathrm{C} \equiv \mathrm{N}$ \\
\hline Mole & 0 & 0.003019 & 0.000471 & 0.003019 & 0.000659 & 0.003019 \\
Mole ratio & \multicolumn{2}{|c|}{0} & \multicolumn{2}{c}{0.156} & \multicolumn{2}{c}{0.218} \\
\hline
\end{tabular}

Table1 continued:

\begin{tabular}{l|ccccccc}
\hline & \multicolumn{2}{|c}{ Group 4 } & \multicolumn{2}{c}{ Group 5 } & \multicolumn{2}{c}{ Group 6 } \\
\cline { 2 - 8 } & $\mathrm{AgNO}_{3}$ & PAN & $\mathrm{AgNO}_{3}$ & PAN & $\mathrm{AgNO}_{3}$ & PAN \\
\hline Mass $(\mathrm{mg})$ & 144 & 160 & 160 & 160 & 176 & 160 \\
Mass ratio $(R(\mathrm{x}))$ & \multicolumn{2}{|c|}{0.9} & \multicolumn{2}{c}{1} & & \multicolumn{2}{c}{1.1} \\
\hline & $\mathrm{Ag}^{+}$ & $-\mathrm{C} \equiv \mathrm{N}$ & $\mathrm{Ag}^{+}$ & $-\mathrm{C} \equiv \mathrm{N}$ & $\mathrm{Ag}^{+}$ & $-\mathrm{C} \equiv \mathrm{N}$ \\
\hline Mole & 0.000848 & 0.003019 & 0.000942 & 0.003019 & 0.001036 & 0.003019 \\
Molar ratio & \multicolumn{2}{|c|}{0.281} & \multicolumn{2}{c}{0.312} & \multicolumn{2}{c}{0.343} \\
\hline
\end{tabular}

$\mathrm{The}_{\mathrm{Ag}}+\mathrm{PAN}$ elastomer with controlled stretchability was tuned by varying the ratio $R(\mathrm{x})$. For control sample (group 1 with $R(0)$ ), no $\mathrm{AgNO}_{3}$ was added. For $\mathrm{Ag}^{+} / \mathrm{PAN}$ elastomers, $R(\mathrm{x})$ started from $R(0.5)$ and increased up to $R(1.1)$ in this study, as listed in the above table. Based on the molecular weight $\left(\mathrm{M}_{\mathrm{w}}\right)$ of PAN (average $\mathrm{M}_{\mathrm{w}}$ : 150,000), and $\mathrm{AgNO}_{3}\left(\mathrm{M}_{\mathrm{w}}: 169.87\right)$, the calculated molar ratios of $\mathrm{Ag}^{+}:-\mathrm{C} \equiv \mathrm{N}$ are also listed in the above table. 
Table S3. The weight percent of residual DMF trapped within $\mathrm{Ag}^{+} / \mathrm{PAN}$ elastomers with various $R(\mathrm{x})$. The position of peak temperature of DMF evaporation and the percentage were extracted from TGA (see Figure S4)

\begin{tabular}{ccc}
\hline Sample name & $\begin{array}{c}\text { Peak temperature } \\
\text { of evaporation }\left({ }^{\circ} \mathrm{C}\right)\end{array}$ & Percent $(\%)$ \\
\hline$R(0)$ & 173 & 8.7 \\
$R(0.5)$ & 173 & 23.5 \\
$R(0.7)$ & 170 & 25.1 \\
$R(0.9)$ & 167 & 27.7 \\
$R(1.0)$ & 168 & 28.7 \\
$R(1.1)$ & 167 & 28.8 \\
\hline
\end{tabular}


Table S4. The sheet resistance of $\mathrm{Ag}^{+} / \mathrm{PAN}$ elastomers with various $R(\mathrm{x})$.

\begin{tabular}{cc}
\hline Sample name & $\begin{array}{c}\text { Sheet Resistance* } \\
(\mathrm{M} \Omega / \mathrm{sq})\end{array}$ \\
\hline$R(0)$ & $\mathrm{N} / \mathrm{A}$ \\
$R(0.5)$ & 26.90 \\
$R(0.7)$ & 23.63 \\
$R(0.9)$ & 13.35 \\
$R(1.0)$ & 8.25 \\
$R(1.1)$ & 5.96 \\
\hline
\end{tabular}

*Note: the sheet resistance was calculated based on the resistance measured using two-probe method and the sample width and length dimension. The decreased sheet resistance is possibly related to the higher density of cyano-silver complex centers and the increased effective electron transport between silver and DMF. ${ }^{10}$ 


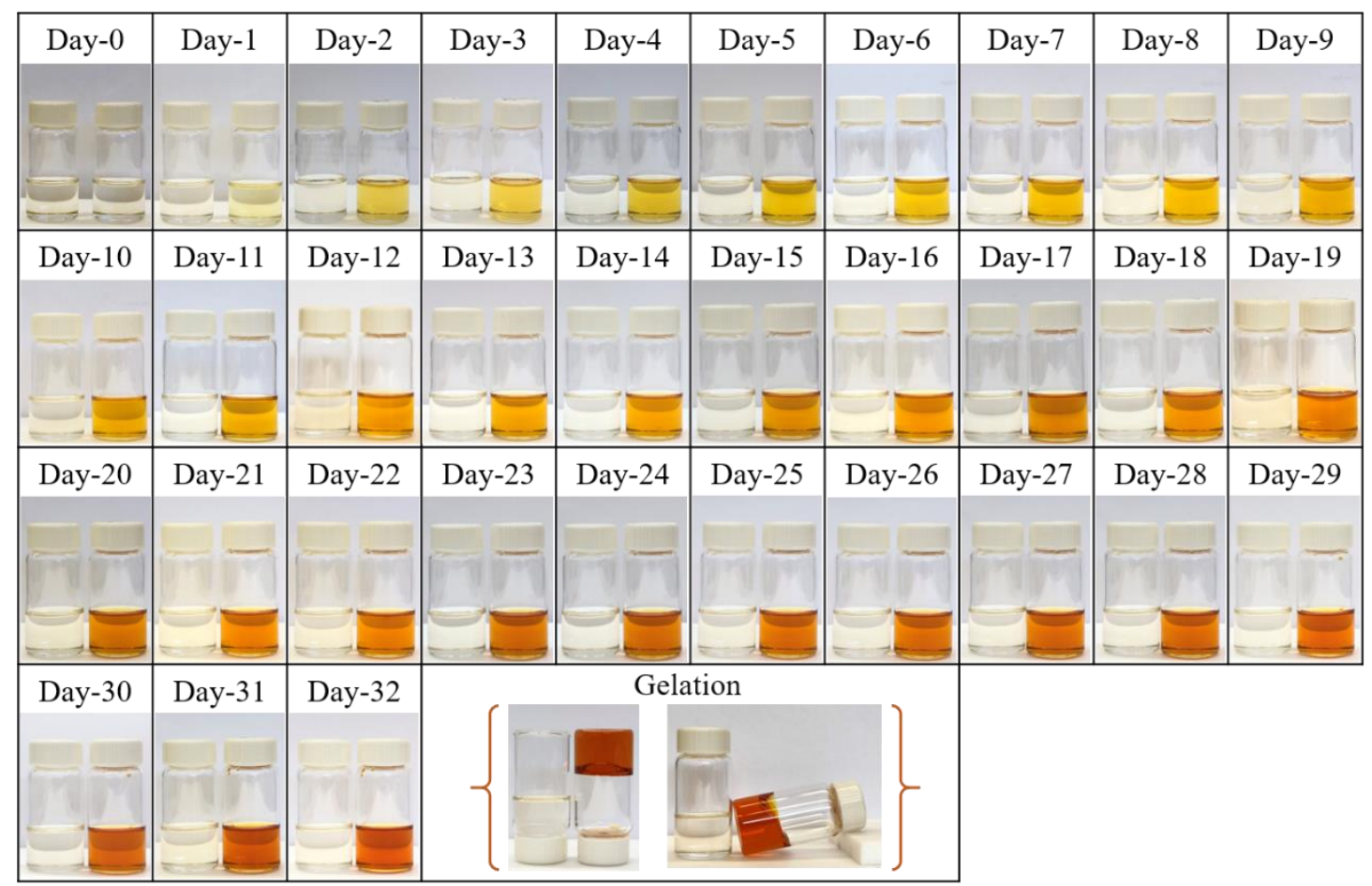

Figure S1. The process (or gelation) of $\mathrm{Ag}^{+} / \mathrm{PAN}$ elastomer with $R(1.0)$ at room temperature. The as-prepared solutions (Day-0, as shown above) of pure PAN (left, with $R(0)$ ) and $\mathrm{AgNO}_{3} / \mathrm{PAN}$ mixture (right, with $R(1.0)$ ) are transparent due to the good dispersing capability of DMF for both $\mathrm{AgNO}_{3}$ and PAN. As time passed by, the color of $\mathrm{AgNO}_{3} / \mathrm{PAN}$ mixture keeps changing to light yellow, brownish, and the final dark red after one month. As a comparison, the color of pure PAN solution after one month was as same as that of the as-prepared solution at Day-0. Gelation was confirmed for $\mathrm{AgNO}_{3} / \mathrm{PAN}$ mixture by the reduced flowability (tilting or up-side-down positioning the vials, also see Video S1), comparing to the DMF-like feature of PAN solutions. This can be attributed to the trapped DMF within the network of PAN polymer chains with coordination bond through cyano-silver complexes, which resulted in a limited flowability of mixture. 


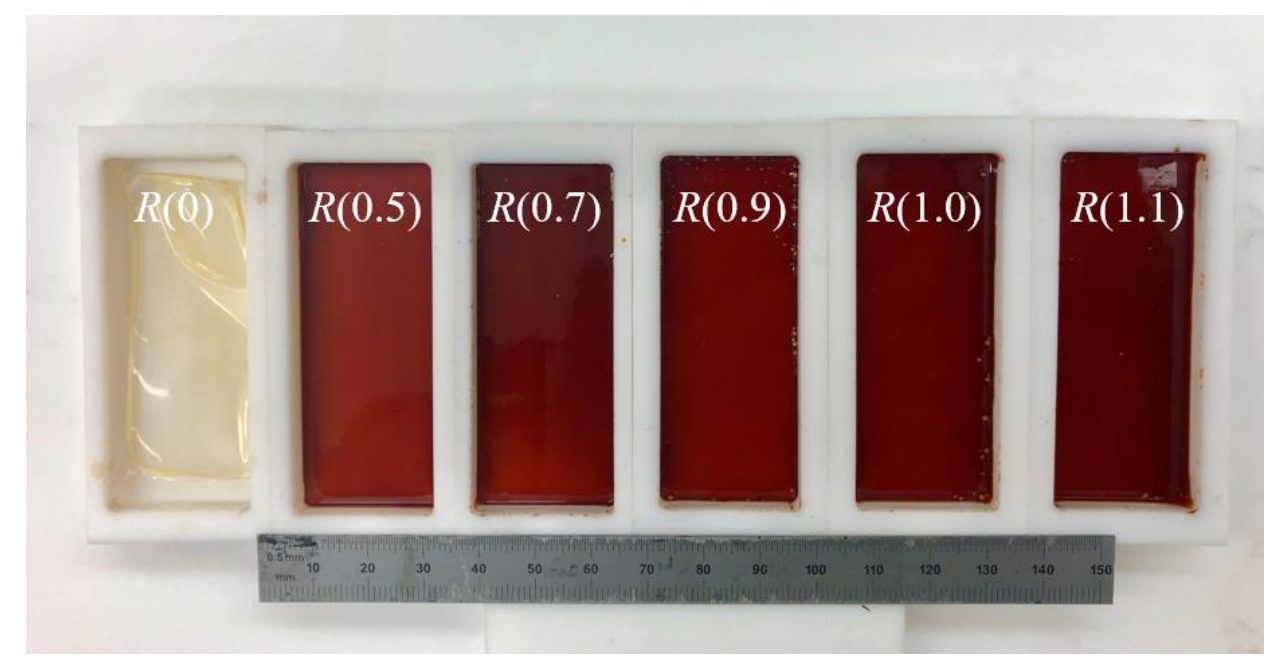

Figure S2. The as-prepared $\mathrm{Ag}^{+} / \mathrm{PAN}$ elastomers with various ratio $R(\mathrm{x})$. The film formation was assisted with Teflon mold using vacuum oven drying. Instead of long time reaction at room temperature (Figure $\mathrm{S} 1$ ), the freestanding $\mathrm{Ag}^{+} / \mathrm{PAN}$ elastomers were obtained using oven drying at elevated temperature of $50{ }^{\circ} \mathrm{C}$ for 36 hours. Due to the high drying temperature (see more details in Supplementary text), the evaporation rate of DMF was increased. As a result, the time needed for the solid gelation of $\mathrm{Ag}^{+} / \mathrm{PAN}$ elastomers was shortened. The final elastomers were dark-red (from $R(0.5)$ to $R(1.1)$ ).

As the ratio, $R(\mathrm{x})$, increased from $R(0.5)$ to $R(1.1)$, the density of coordination bond of cyanosilver complexes increased, too. Therefore, more residual DMF solvent after drying at $50{ }^{\circ} \mathrm{C}$ was trapped within the as-prepared elastomers due to the densely interconnected polymer chain structure with more nano-reservoirs (see Figure S4 for the residual DMF weight percent for elastomers with different $R(\mathrm{x})$ ). Because of the special internal structures of two phases with nano-reservoirs for $\mathrm{DMF}$, the prepared $\mathrm{Ag}^{+} / \mathrm{PAN}$ elastomer showed an unexpected stretchability while increasing the ratio $R(\mathrm{x})$ (see more details in Supplementary text). 


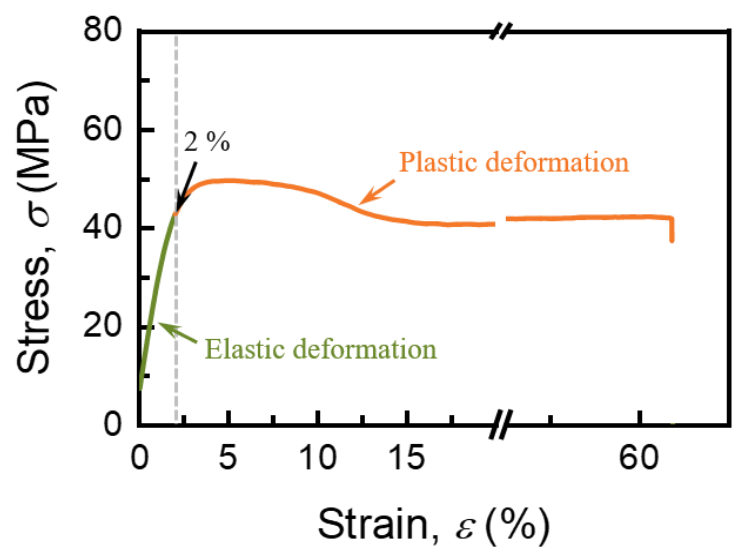

Figure S3. The elastic and plastic deformation of pure PAN film with $R(0)$. Although a total failure strain of averaged at $60 \%$ can be achieved for PAN film with $R(0)$, the elastic deformation happened only in a small strain range of less than $2 \%$, as indicated in the above figure. The plastic deformation resulted in permanent residual strain with no capability of recovery when external force was absent. Therefore, PAN film with $R(0)$ can't be regarded as an elastomer (only $2 \%$ elastic deformation). This made the stretchability of $\mathrm{Ag}^{+} / \mathrm{PAN}$ elastomer with $R(1.0)$ (up to $600 \%$ ) astonishingly remarkable. 


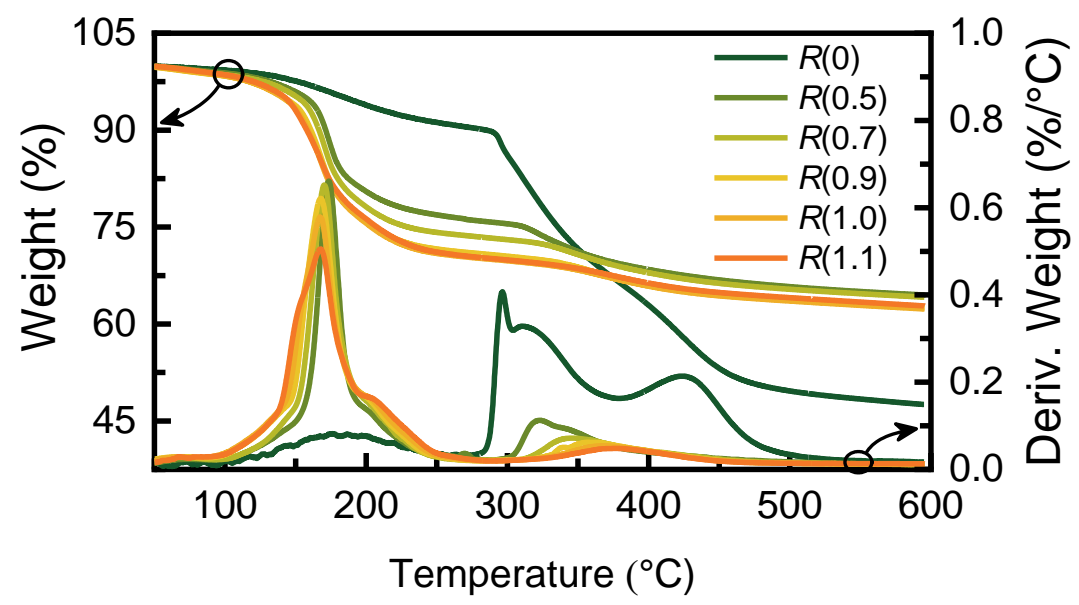

Figure S4. The thermogravimetric analysis (TGA) of DMF weight percent trapped within $\mathrm{Ag}^{+} / \mathrm{PAN}$ elastomers (dried at $50^{\circ} \mathrm{C}$ ). Two peaks of derivative weight change were observed. The first one, at $\sim 170{ }^{\circ} \mathrm{C}$, was ascribed to the evaporation temperature of DMF. The other one, at $300-400{ }^{\circ} \mathrm{C}$ corresponded to the decomposition of PAN polymer and the PAN polymer with coordination bond by cyano-silver complexes. The weight percent of DMF was listed in Table S3. Once the network formed by cyano-silver complexes (e.g.: elastomer of $R(0.5)$ ), the percentage of trapped DMF 'lubricant' within the nano-reservoirs was significantly higher than that of pure PAN film with $R(0)$. The residual $8.7 \mathrm{wt}$. \% DMF for $R(0)$ may be resulted from the strong van der Waals interactions between DMF and PAN which defeated by the mild drying condition of $50{ }^{\circ} \mathrm{C}$. Percent of trapped DMF increased to the maximum value of 28.8 wt. $\%$ in this study, as the ratio, $R(\mathrm{x})$, raised to 1.1 . The trapped DMF within nanoreservoirs assisted the fluidity of PAN chains under external deformation. These speculations corresponded to the mechanical response as shown in Figure 2A, Figure S5, and the illustration in Figure 4D. 


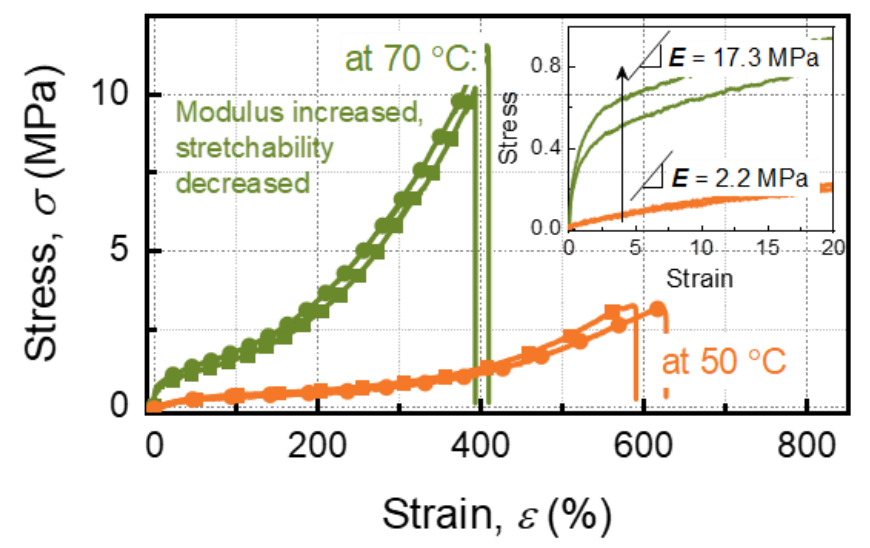

Figure S5. The comparisons of mechanical response for $\mathrm{Ag}^{+} / \mathrm{PAN}$ elastomers with $R(1.0)$ dried at $50{ }^{\circ} \mathrm{C}$ and $70{ }^{\circ} \mathrm{C}$. Drying at $70{ }^{\circ} \mathrm{C}$ significantly changed the mechanical performance of $\mathrm{Ag}^{+} / \mathrm{PAN}$ elastomer: decreased stretchability ( 400\%) and increased elastic modulus ( 17.3 MPa), comparing to the case of drying at $50{ }^{\circ} \mathrm{C}$. Higher drying temperature resulted in less DMF 'lubricant' within the nano-reservoirs, therefore, leading to relatively restricted movement of coordination-bonded PAN chains. However, a significant amount of DMF was still trapped within the elastomer, instead of a complete depletion of DMF (e.g.: the cases dried at $90{ }^{\circ} \mathrm{C}$ or $150{ }^{\circ} \mathrm{C}$ ). Thus, the $\mathrm{Ag}^{+} / \mathrm{PAN}$ elastomer with $R(1.0)$ (dried at $70{ }^{\circ} \mathrm{C}$ ) was still considerably stretchable with a trade-off being tough, comparing to the case dried at $50{ }^{\circ} \mathrm{C}$. 


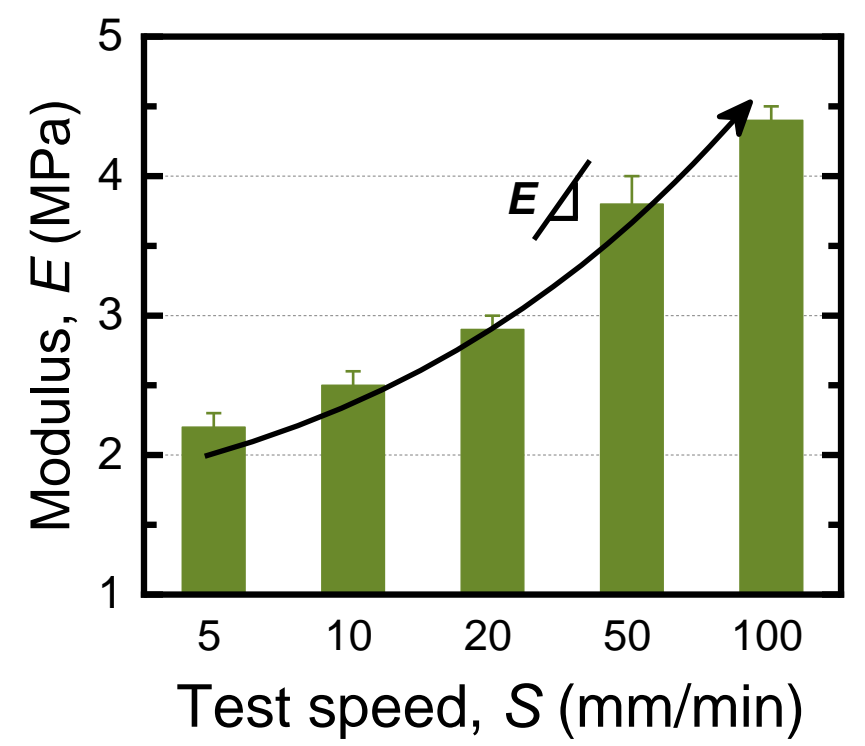

Figure S6. The engineering modulus of $\mathrm{Ag}^{+} / \mathrm{PAN}$ elastomer with $R(1.0)$ at different test speed, $S$, ranging from $5 \mathrm{~mm} \cdot \mathrm{min}^{-1}$ to $100 \mathrm{~mm} \cdot \mathrm{min}^{-1}$. These data were extracted from curves in Figure 2C. Both increased modulus and failure stress indicated a feature of thermoset polymers, of which mechanical properties showed strong dependence on the strain rate (test speed, $S$ ), because of the densely interconnected network of PAN chains. 

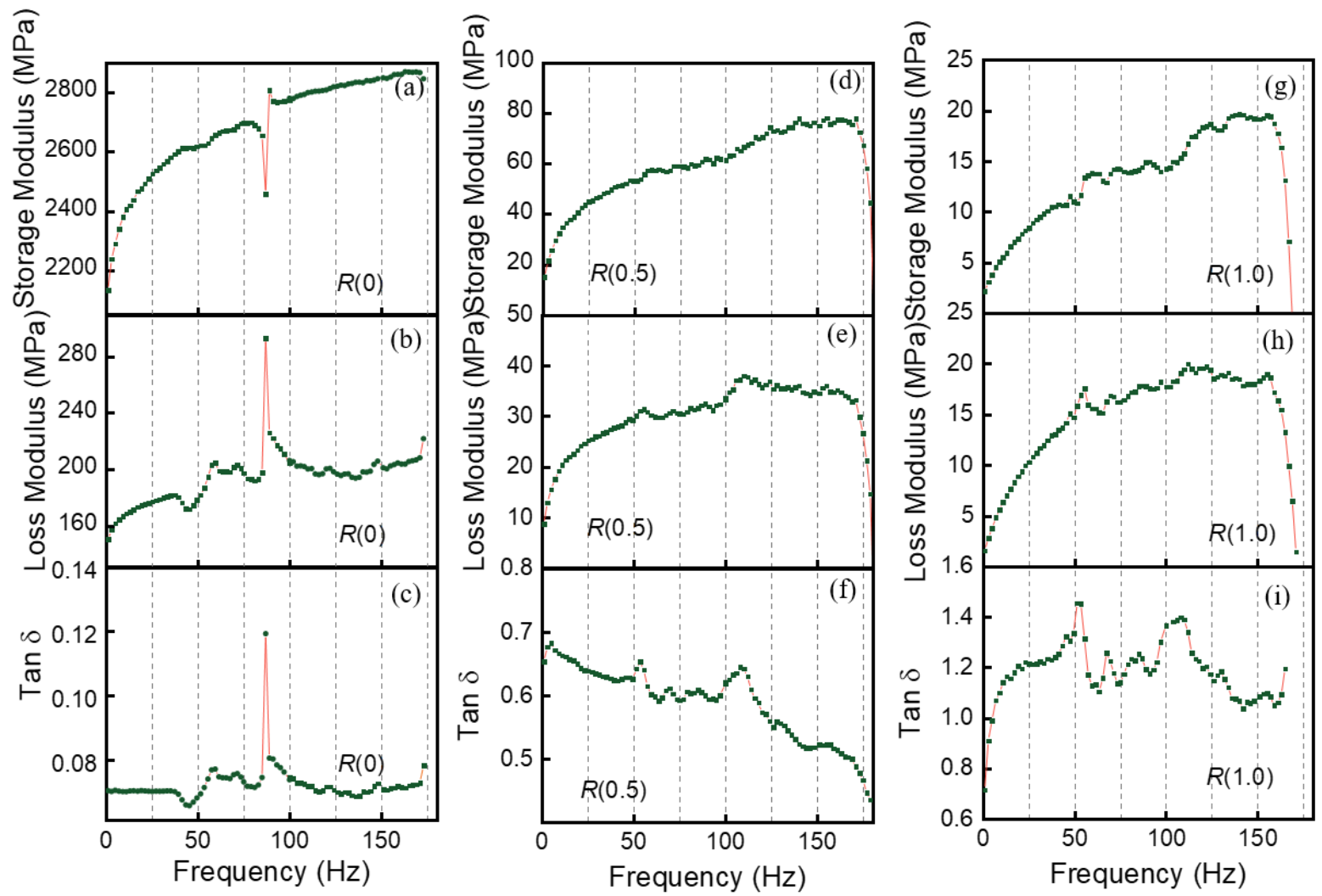

Figure S7. The storage modulus, loss modulus, and tan $\delta$ of Ag+/PAN elastomer with (a-c) $R(0)$, (d-f) $R(0.5),(\mathrm{g}-\mathrm{h}) R(1.0)$ as a function of frequency. For all tested samples, both storage modulus and loss modulus were more frequency dependent from $1 \mathrm{~Hz}$ to $50 \mathrm{~Hz}$, as compared to the higher frequency range. As a contrast to the sample with $R(0), \mathrm{Ag}^{+} / \mathrm{PAN}$ elastomers with $R(0.5)$ and $R(1.0)$ possess a much larger $\tan \delta$, indicating that loss modulus is predominant. Therefore, the viscous behavior of the elastomer could endow a good polymer chain fluidity and entanglement corresponding to improve stretchability while maintaining a sufficient storage modulus. 


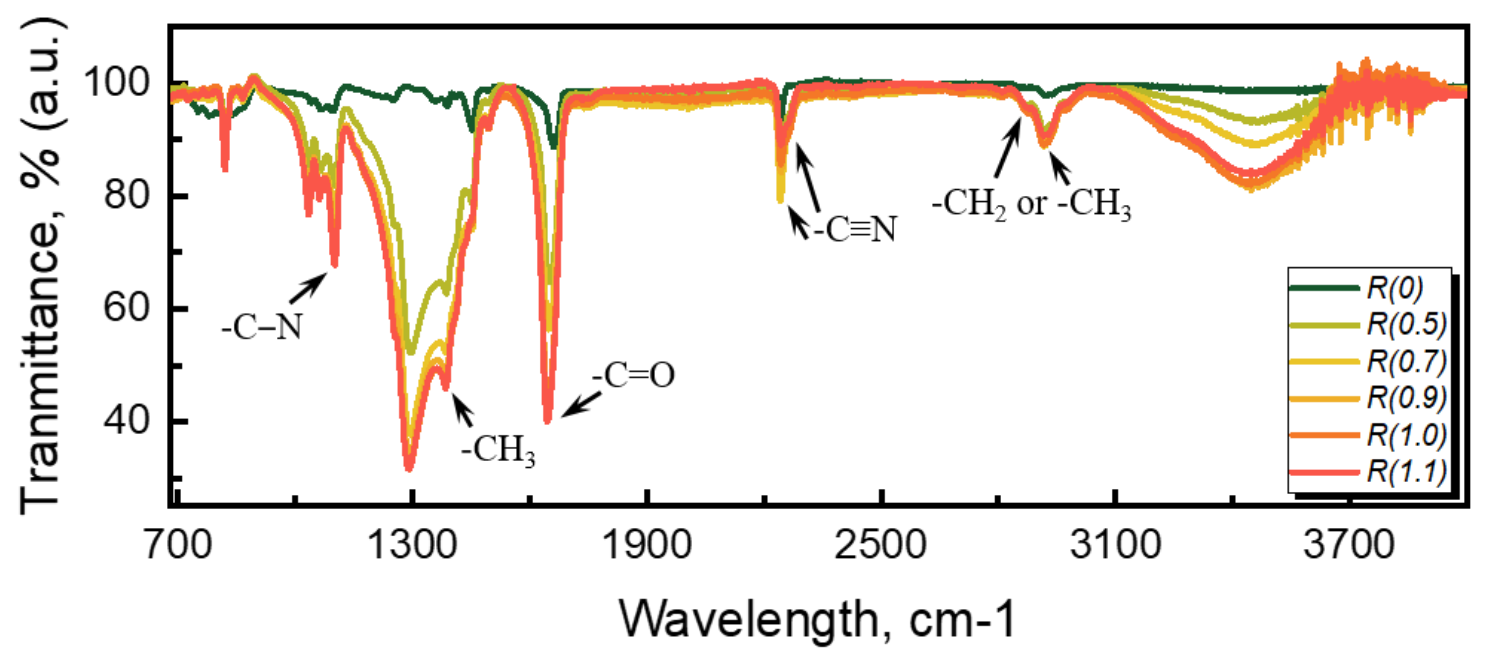

Figure S8. The ATR-FTIR spectra of $\mathrm{Ag}^{+} / \mathrm{PAN}$ elastomers. The PAN film with $R(\mathrm{x})$ had characteristic peaks at $2921 \mathrm{~cm}^{-1}$ and $2870 \mathrm{~cm}^{-1}$ which were ascribed to the stretching vibration of $-\mathrm{CH}_{2}$ or $-\mathrm{CH}_{3}$ of the backbone, and a peak at $2246 \mathrm{~cm}^{-1}$ corresponded to the stretching vibration of $-\mathrm{C} \equiv \mathrm{N}$ (see Figure $2 \mathrm{D}$ for the difference of elastomers with various $R(\mathrm{x}))^{11}$. All samples showed characteristic peaks of DMF at $1650 \mathrm{~cm}^{-1}$ (for $-\mathrm{C}=\mathrm{O}$ ), $1390 \mathrm{~cm}^{-1}$ (for $-\mathrm{CH}_{3}$ ), and $1092 \mathrm{~cm}^{-1}$ (for $\left.-\mathrm{C}-\mathrm{N}\right)^{12}$. 

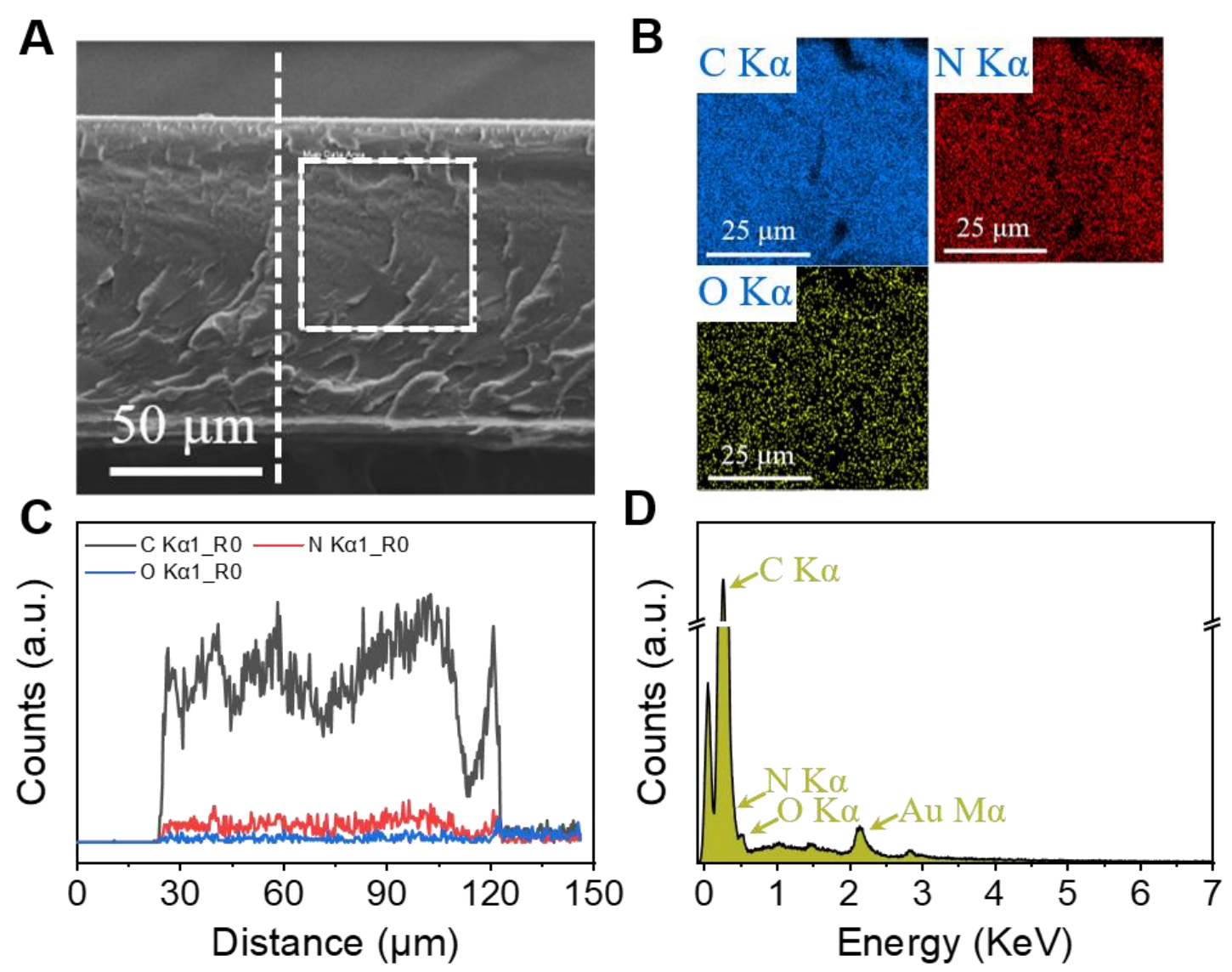

Figure S9. The elemental compositions of pure PAN film with $R(0)$. (A) The cross-section of pure PAN film. To obtain fresh and clean cross-section, instead of cutting using blade, SEM samples were prepared by breaking liquid nitrogen frozen film. The texture implies a rough morphology. (B) The elemental mapping of $\mathrm{C} \mathrm{K} \alpha, \mathrm{N} \mathrm{K \alpha}$, and $\mathrm{O} \mathrm{K} \alpha$ from the dash-line square area in (A). (C) Line-scan profile from the site as indicated by dash-line in (A). (D) Spectrum collected from the dash-line square area in (A), showing a K $\alpha$ edge absorption of oxygen. It confirms the existence of DMF and correlates with the TGA data of PAN film $(R(0))$ in Figure S4. 

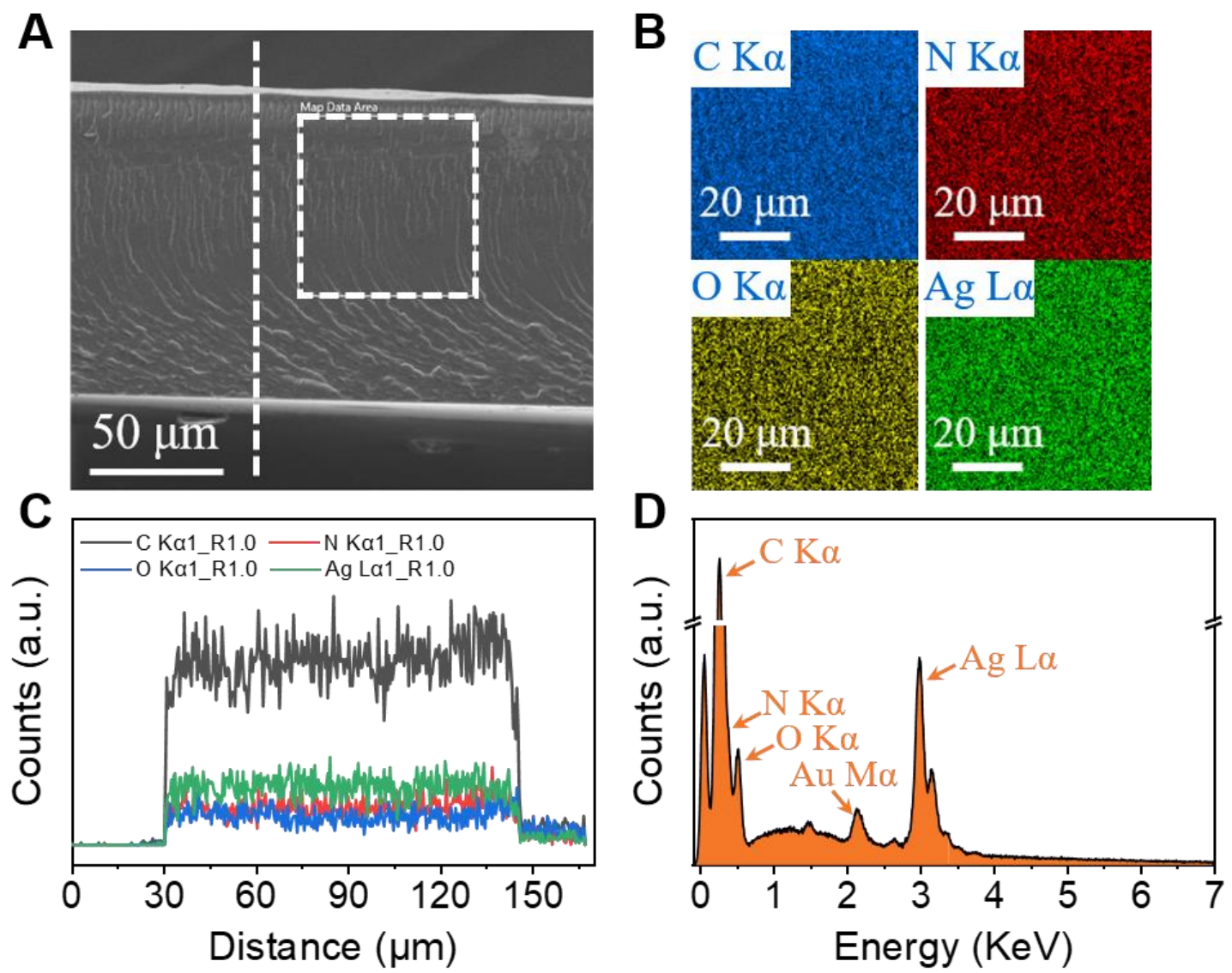

Figure S10. The elemental compositions of $\mathrm{Ag}^{+} / \mathrm{PAN}$ elastomers with $R(1.0)$. (A) The crosssection of $\mathrm{Ag}^{+} / \mathrm{PAN}$ elastomer. Same method was used to prepare the SEM sample for EDX mapping as stated earlier in Figure S9. Random texture still showed up. (B) The elemental mapping of $\mathrm{C} \mathrm{K} \alpha, \mathrm{N} \mathrm{K} \alpha, \mathrm{O} K \alpha$, and $\mathrm{Ag} \mathrm{L} \alpha$ from the dash-line square area in (A).

Homogeneous distribution including silver was confirmed. (C) Line-scan profile from the site indicated by dash-line in (A), displaying homogeneous distributions of $\mathrm{C}, \mathrm{N}, \mathrm{O}$, and $\mathrm{Ag}$ through thickness. (D) Spectrum collected from the dash-line square area in (A), showing an obvious L $\alpha$ edge absorption of silver. It confirms the existence of silver ion since no silver particles were found from SEM (microscale) or HRTEM (nanoscale). 

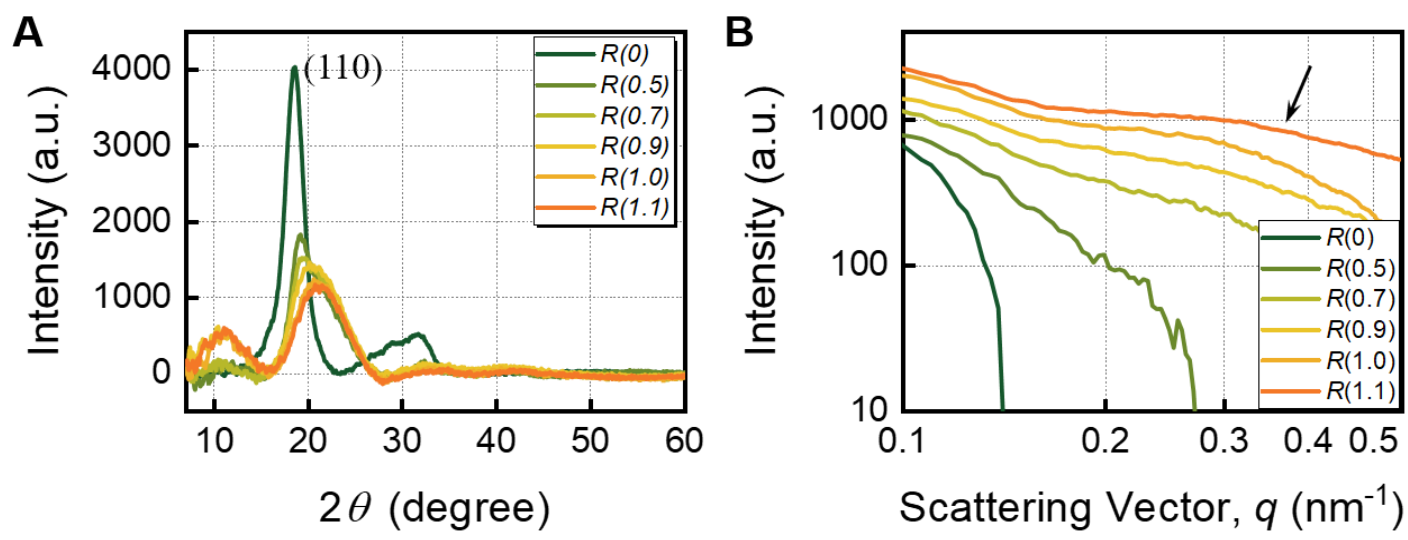

Figure S11. The small- and wide-angle X-ray scattering (SAXS and WAXS) of $\mathrm{Ag}^{+} / \mathrm{PAN}$ elastomers with the ratio from $R(0)$ to $R(1.1)$. (A) The intensity (a.u.) of WAXS as a function of $2 \theta$ (degree). The pure PAN film with $R(0)$ showed a sharp crystalline peak at 17 (degree) and a broad non-crystalline peak at 25-35 (degree) $)^{13}$. However, this characteristic peak (at 17 degree, the orthorhombic PAN (110) reflection) was suppressed and broadened for $\mathrm{Ag}^{+} / \mathrm{PAN}$ elastomers (from $R(0.5)$ to $R(1.1)$ ), indicating a less crystalline structure, which corresponds to the supplementary text. An even broader non-crystalline peak (not obvious) for elastomers with $R(0.5)$ to $R(1.1)$ was observed. No other peaks of silver crystals (e.g.: (111), (200), (220) of the face center cubic phase) were recorded, implying the existence of cyano-silver complexes, or low trace of silver crystalline particles. (B) The intensity (a.u.) of SAXS as a function of the scattering vector, $q\left(\mathrm{~nm}^{-1}\right)$ with a log scale. An increased scattering is due to the increased silver with the raise of $R(\mathrm{x})$. 


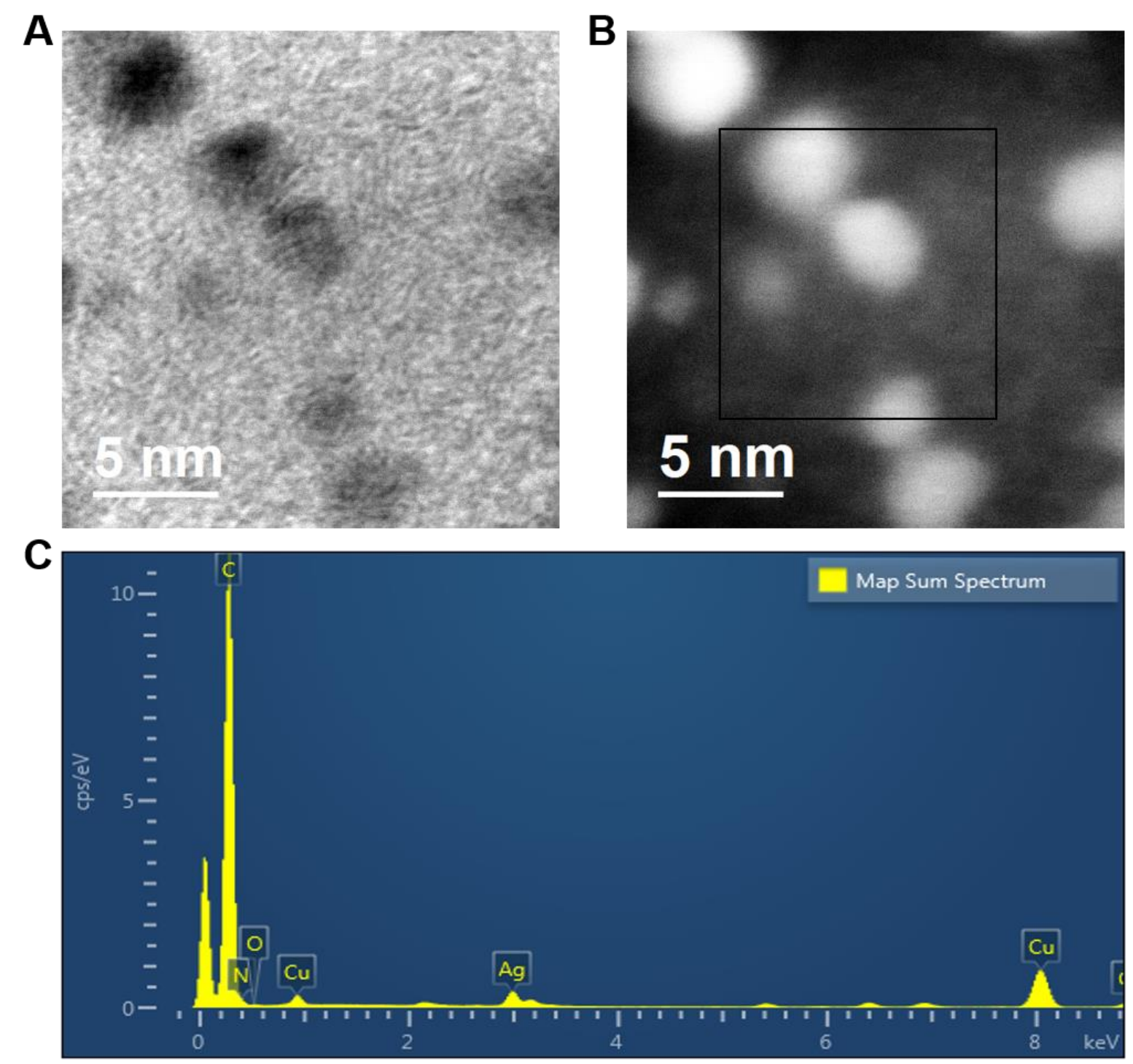

Figure S12. STEM BF and ADF images, and its corresponding EDX spectrum and mapping (see Figure 2H). (A) STEM BF image. (B) STEM ADF image. (C) The accumulative spectrum data from the black square area in ADF image. The contrast difference in BF image originated from the difference in atomic number of different elements, which was more obvious in ADF images. This assumption was verified by the STEM EDX mapping of the black square area of ADF images as shown in Fig. $2 \mathrm{H}$ with clearly seen $\mathrm{C}, \mathrm{N}, \mathrm{O}$, and Ag. The spectrum in (C) also supported existence of these elements. 


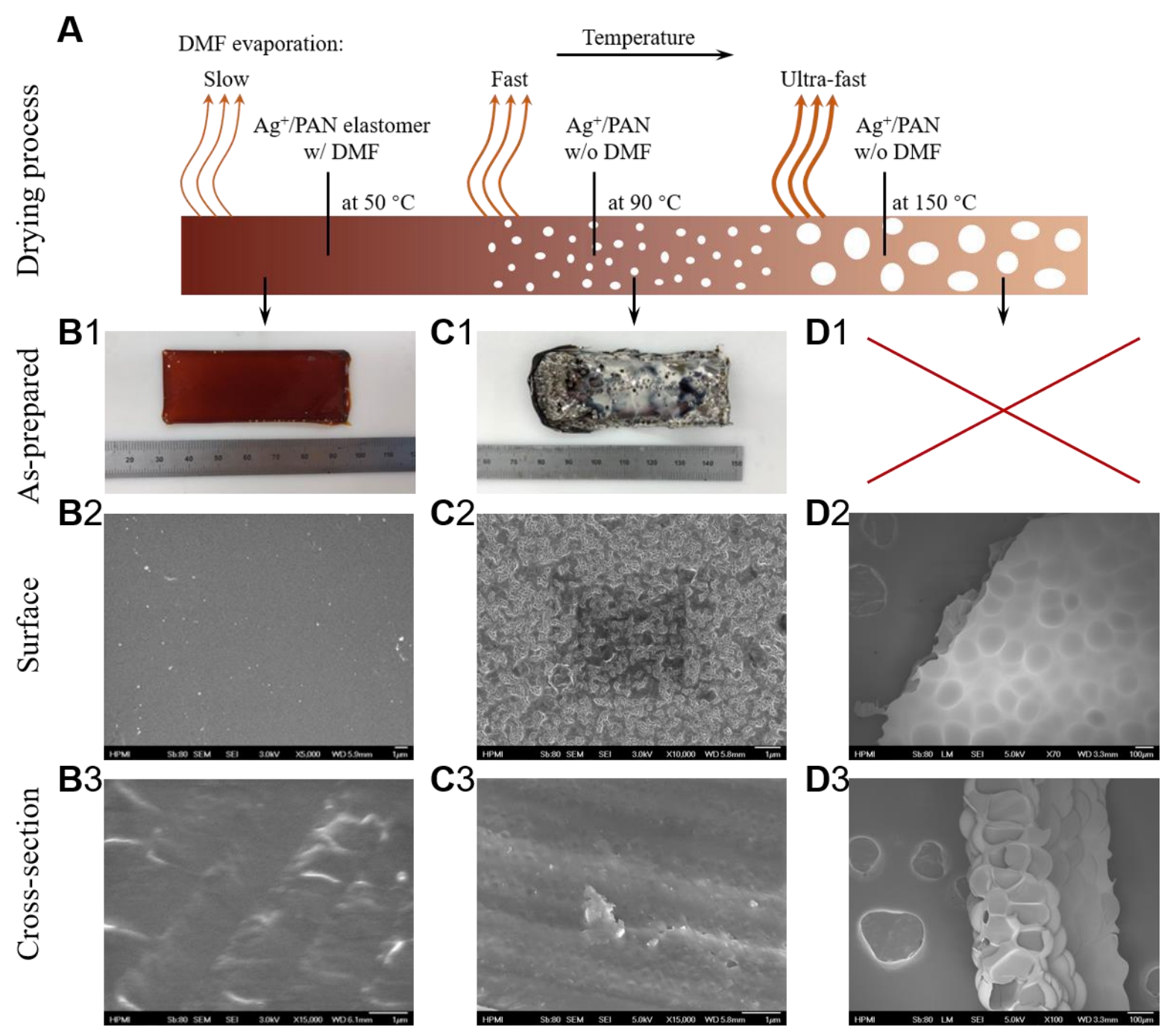

Figure S13. The microstructure of $\mathrm{Ag}^{+} / \mathrm{PAN}$ elastomers dried at different temperature. (A)

The illustration of internal microstructure formation while varying the drying condition from $50{ }^{\circ} \mathrm{C}, 90{ }^{\circ} \mathrm{C}$, to $150{ }^{\circ} \mathrm{C}$. (B1) Digital images of as-prepared sample (dried at $50{ }^{\circ} \mathrm{C}$ ), (B2) its surface and (B3) cross-section morphology. Similarly, the corresponding digital and SEM images for the case of sample dried at $90{ }^{\circ} \mathrm{C}$ and $150{ }^{\circ} \mathrm{C}$ were shown in C1-C3 and D1-D3, respectively (see supplementary text for more detailed explanation). 

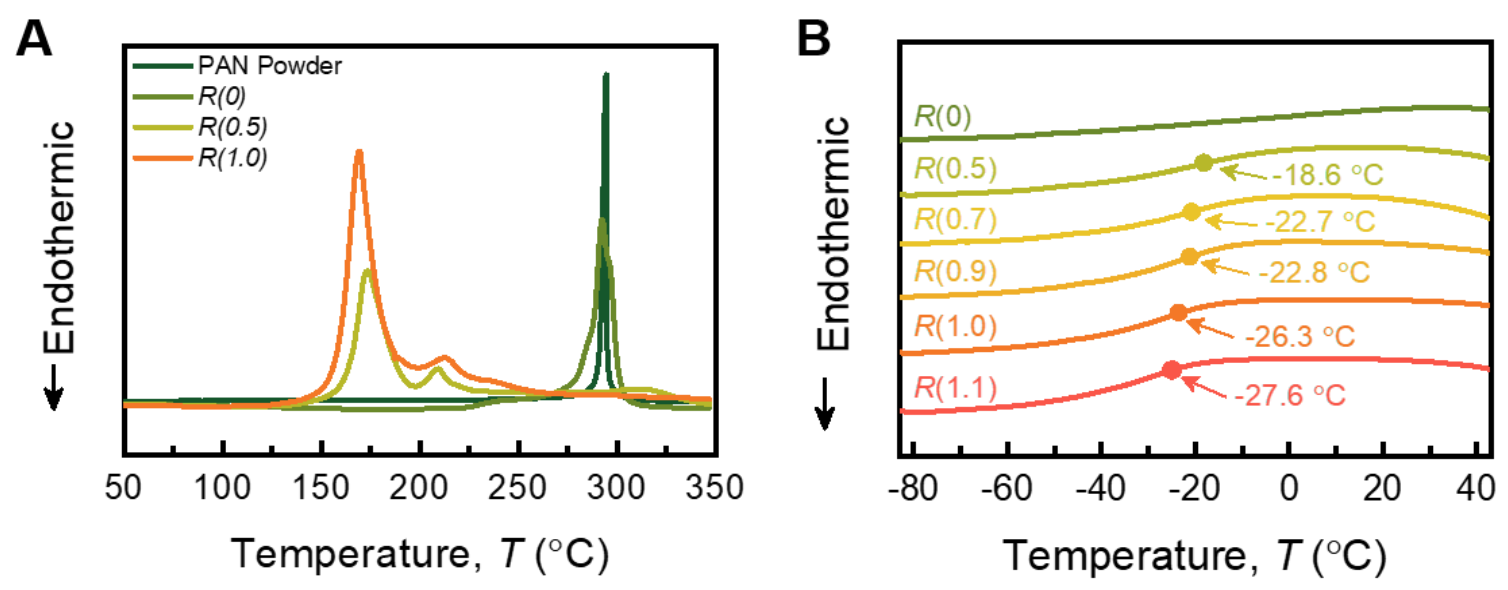

Figure S14. The differential scanning calorimetry (DSC)of PAN powder (as-received) and $\mathrm{Ag}^{+} / \mathrm{PAN}$ elastomers with various $R(\mathrm{x})$ (as-prepared). (A) The heat flow (a.u.) as a function of temperature for PAN powder, and elastomers with $R(0), R(0.5)$, and $R(1.0)$. The exothermic peak of decomposition of PAN was confirmed at $\sim 290^{\circ} \mathrm{C}$ for PAN powder and the elastomer with $R(0)$ (nearly close to the melting point of PAN at $300{ }^{\circ} \mathrm{C}$ ). However, the temperature peak of DMF evaporation at $\sim 170{ }^{\circ} \mathrm{C}$ was recorded for elastomers with $R(0.5)$ and $R(1.0)$, which corresponded to the TGA data. Additional temperature peak at $\sim 210^{\circ} \mathrm{C}$ was possibly attributed to the decomposition temperature of $\mathrm{Ag}^{+}$coordination-bonded PAN, which, as a comparison, was lowered from $\sim 290{ }^{\circ} \mathrm{C}$ of PAN powder and PAN film with $R(0)$. (B) All asprepared elastomers have $T_{\mathrm{g}}$ (glass transition temperature) values (filled dot, pointed by an arrow with a text label of temperature) bellow room temperature with an exception for $R(0)$, for which no obvious heat flow transition (e.g.: transition is too broad) was located in the full temperature range test. 


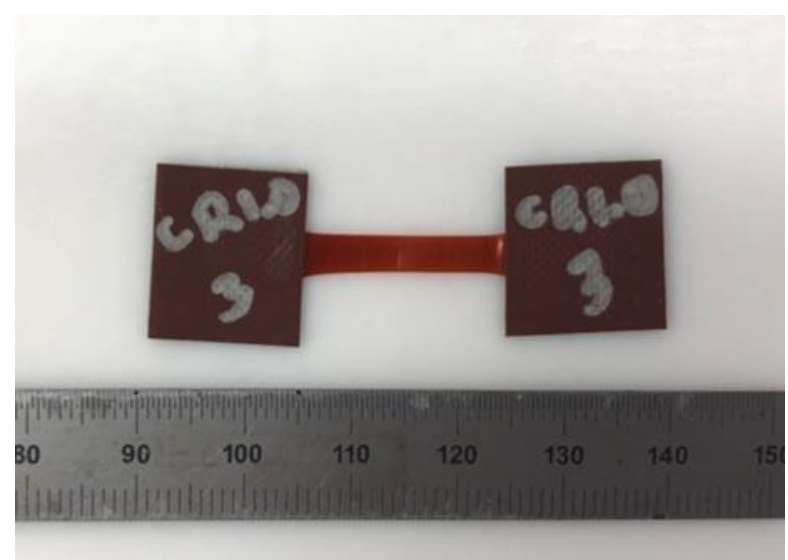

Figure S15. Deformation with residual strain ( 90\% recovery) of sample after releasing from the $600 \%$ stretching with an interval time of 24 hours. 


\section{Video S1.}

The as-prepared PAN solution and $\mathrm{Ag}^{+} / \mathrm{PAN}$ mixture, and the solution after one month at room temperature.

\section{Video S2.}

The super stretchability of $\mathrm{Ag}^{+} / \mathrm{PAN}$ elastomers.

\section{Video S3.}

The electrical response of $\mathrm{Ag}^{+} / \mathrm{PAN}$ elastomer film while stretching and releasing.

Video S4.

The electrical response of $\mathrm{Ag}^{+} / \mathrm{PAN}$ elastomer film while being blowing with air (arrows indicate the start of air blow from mouth). 


\section{References}

1. Wang, S.; Xu, J.; Wang, W.; Wang, G. N.; Rastak, R.; Molina-Lopez, F.; Chung, J. W.; Niu, S.; Feig, V. R.; Lopez, J.; Lei, T.; Kwon, S. K.; Kim, Y.; Foudeh, A. M.; Ehrlich, A.; Gasperini, A.; Yun, Y.; Murmann, B.; Tok, J. B.; Bao, Z. Nature 2018, 555, 83-88.

2. Markvicka, E. J.; Bartlett, M. D.; Huang, X.; Majidi, C. Nature Materials 2018, 17, (7), 618-624.

3. Matsuhisa, N.; Kaltenbrunner, M.; Yokota, T.; Jinno, H.; Kuribara, K.; Sekitani, T.; Someya, T. Nat Commun 2015, 6, 7461.

4. Zhang, S.; Park, J. G.; Nguyen, N.; Jolowsky, C.; Hao, A.; Liang, R. Carbon 2017, $125,649-658$.

5. $\quad$ Zhang, S.; Hao, A.; Nguyen, N.; Oluwalowo, A.; Liu, Z.; Dessureault, Y.; Park, J. G.; Liang, R. Carbon 2019, 144, 628-638.

6. Zhao, X.; Chen, F.; Li, Y.; Lu, H.; Zhang, N.; Ma, M. Nat Commun 2018, 9, (1), 3579. 7. Jolowsky, C.; Sweat, R.; Park, J. G.; Hao, A.; Liang, R. Composites Science and Technology 2018, 166, 125-130.

8. Hirschl, C.; Neumaier, L.; Puchberger, S.; Mühleisen, W.; Oreski, G.; Eder, G. C.; Frank, R.; Tranitz, M.; Schoppa, M.; Wendt, M.; Bogdanski, N.; Plösch, A.; Kraft, M. Solar Energy Materials and Solar Cells 2015, 143, 494-502.

9. Mrozek, R.; Cole, P. J.; Lenhart, J. L. Effect of Sol Molecular Weight on the Mechanical Properties and Sol Migration in Polymer Gels; Sandia National Lab.(SNL-NM), Albuquerque, NM (United States); Sandia ...: 2007.

10. Sun, L.; Hendon, C. H.; Dinca, M. Dalton Trans 2018, 47, (34), 11739-11743.

11. Qin, L.; Zhao, Y.; Liu, J.; Hou, J.; Zhang, Y.; Wang, J.; Zhu, J.; Zhang, B.; Lvov, Y.; Van der Bruggen, B. ACS Appl Mater Interfaces 2016, 8, (50), 34914-34923.

12. Zhang, Y.; Yang, B.; Li, K.; Hou, D.; Zhao, C.; Wang, J. RSC Advances 2017, 7, (89), 56183-56193.

13. Zhang, Z.; Zhang, L.; Wang, S.; Chen, W.; Lei, Y. Polymer 2001, 42, (19), 83158318. 